\title{
Textile Intelligence, a Social Row Material
}

\author{
Zivia Kay* \\ Academy of Art and Design, Bezalel University; Israel
}

Submission: May 12, 2018; Published: June 12, 2018

*Corresponding author: Zivia Kay, Academy of Art and Design, Bezalel University; Mount Scopus, P.0. Box 24046, Jerusalem 9124001, Israel, Tel: +972542087969; Email: ziviakl@gmail.com

\begin{abstract}
Fashion futurists predict, among other things, that the ritual of standing before the mirror will be replaced by new dressing mechanisms when using intelligent textiles to obtain an aptly designed covering. A value-minded perusal of the new realms of consciousness and conceptualization generated by smart textiles calls for advanced study based on theories of sustainable planning and material culture, striving to measure and examine the influence of smart textiles on the environment and on the users. Will the need to dress each time anew be eliminated, or will users adopt new perceptions regarding the limits of human ability? These questions reinforce the argument that cultural and social changes may be introduced via textile intelligence. A journey into the unknown of solar shirts with a refreshable cut and grows able seasonal sleeves, explores the possibility of their becoming the commons, as well as the cost of their accessibility.
\end{abstract}

Keywords: Textile Intelligence; Material culture; Fashion; Sustainability; Social change

\section{Introduction}

Fashion as means of communication produces meanings, establishes aesthetic values and maintains power relations within culture. A fashion reality influenced by the possibilities of mass production and globalized economy becomes public domain within the span of a single sunrise. Implementing intelligent textiles in clothing/fashion can turn the scientific development into an integral part of the routine for the majority of material and conceptual culture consumers the world over. It might then shift control over the new opportunity of using smart textiles, to the wider public, defining new common capital that could possibly leverage a socio-cultural change [1].

A theoretical basis in support of the argument that social and cultural changes may be introduced via 'very smart textiles'. Charging of textile intelligence with the dimensions of reality is performed by designers, manufacturers, material researchers, technologists, engineers, and industrialists [2]. Will their meticulous heritage become a passing research episode in the future which will merely provide a pointed scientific response to the field of development, or will it help promote a change in economic and social states of mind, transforming smart textiles into the norm for the majority of consumers of material and conceptual culture worldwide?

I argue that such change requires research based on theories of sustainable planning which ethically examine phenomena expected to significantly influence the majority of mankind «upstream» in the future [3]. The validity of such a discussion will form the basis for comprehensive future research aimed at pinpointing processes that may introduce social and cultural change and offering guidance for the production of smart textiles.

In order to reaffirm this working claim, the discussion should center on the points shared by the technological vision of smart textiles and contemporary social, cultural and environmental theories referring to the future and its characteristics.

\section{Textile as a Cultural Signifier}

Textiles have alluded to material culture for nearly 11 millennia (Figure 1) The roots of the metaphor «text and textile» point at a material characterized by intertwined technical and cultural aspects. The conceptual perception of these two cultural milestones has spawned languages of communication transpiring along common axes that have drawn meanings and symbols from each other [4]. Textile as a text of fashion functions as a bridge between material culture and visual meaning, from the definition of identity and the structuring of social status to an inter textual work comprising virtual images [5]. The experience of social liberation has been transformed from a personal asset to an economic commodity in the fashion world (Figure $2 \& 3$ ). A multi-dimensional weaving technology embeds text into textile, converting the body, in the service of fashion, into an unequivocal time- and gaze-dependent frame. 


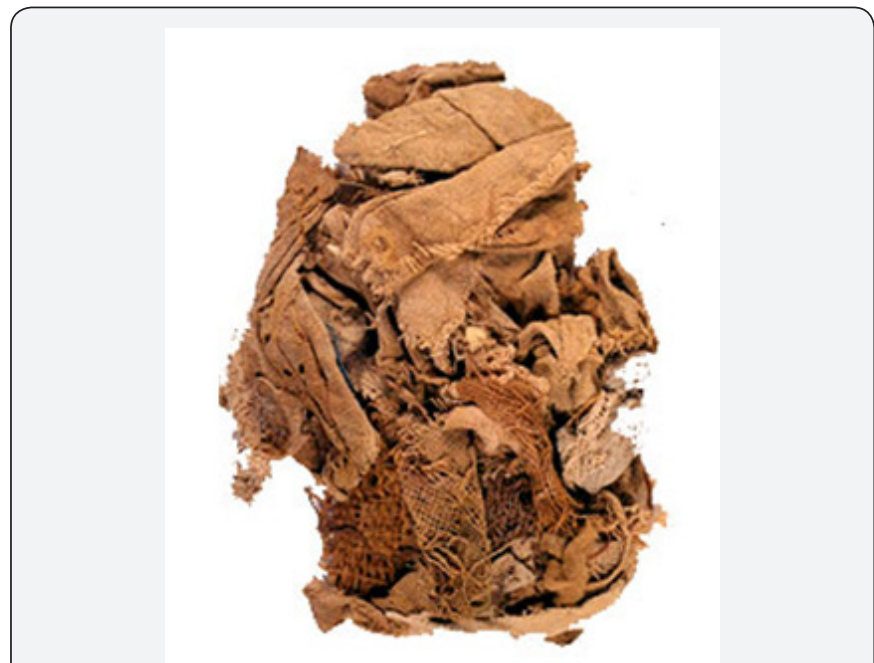

Figure 1: Cloth aged 9,000 years, Organic Archive, Israeli National Antiquities Treasures.
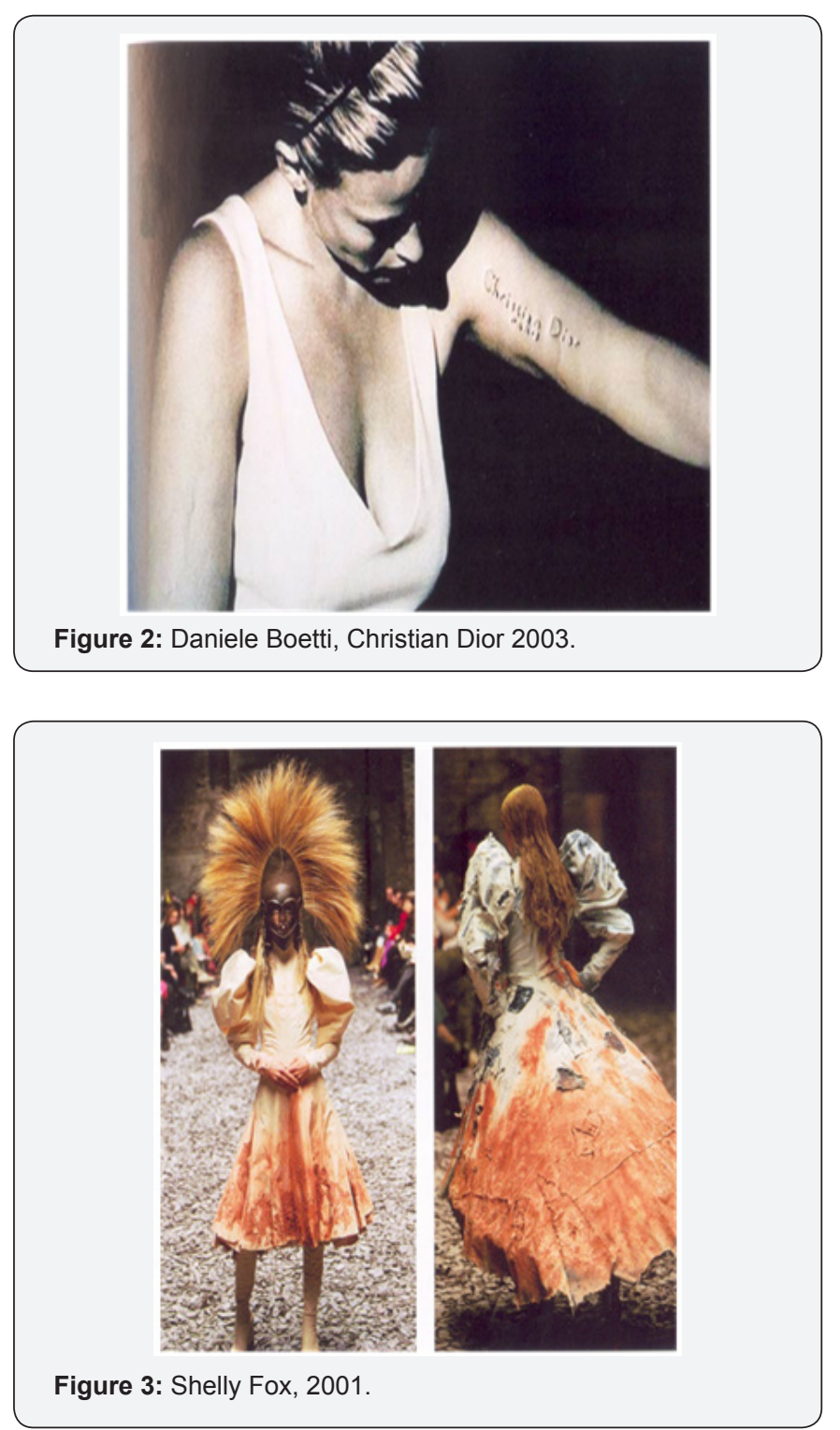

\section{Intelligent and Interactive Textiles}

Xiaoming Tao [2] claims that smart technologies and materials is one of the convergence results of sciences. He describes fabrics capable of sensing and responding to stimuli due to their structure. Sensors are incorporated into the cells of smart and active systems, which identify a phenomenon, convert it into movement, a chemical change, a composition, adapting or reproducing an apt response [6-8]. Very smart materials react and initiate action from a set of pre-programmed instructions. Such units possess cerebral abilities: cognition, logic, and decision-making ability.

Lena Berglin [9] discussed smart textiles and their predicted future influence on everyday life, specifying major areas of development. According to Berglin, the interdisciplinary professions associated with such developments include textile technology and design, computing technology: hardware and software, material science, signal processing, product design, interaction, and system design. This widespread trend does not include ecologists, sociologist, fashion designers and other professions that might consider non-physical aspects of intelligent textile development.

\section{Social and Cultural Psychology of Textiles}

Many parts of our physical world hold no ethical significance for us. Our awareness of the elements comprising the material environment usually amounts to an understanding of their function or an assessment of their visible and marketed quality. Enlightened contemporary use defines that the designed and fashionable are preferable, more convenient and pleasurable to live around, they convey up-to-datedness and make for safe social positioning. Further to this reality the meaning of apparel is examined in the equation of self-definition and within the social and reflexive configuration of a life borrowed from visual images.

Theories challenging prevalent cultural perceptions of body and identity likewise postulate that fashion is a dissemination route for dialects of information. Irit Rogoff [10] maintains that apparel is a language of communication [11]. Judith Butler regards apparel as a vehicle for the construction of identity. Holly L Schrank [12] chose the diffusion of fashion innovations and inventions as the object of a study which examined psychological, sociological, and economic variables. It is only natural to assume, she argues, that these processes are also relevant in practices of social admission and rejection in local systems.

\section{Discussion}

From a socio-cultural point of view, intensive assimilation of textile intelligence in fashion may dictate new boundaries for the creation of personal identity, change the body fostering culture, the sense of social belonging, and violate the balance underlying the triad: production-consumption-fashion. In this context, mutually-dependent major dilemmas are on the agenda today: 


\section{Current Trends in Fashion Technology \& Textile Engineering}

one concerns the gap between the technological vision of dirtrepellent, memory-possessing, temperature-sensitive textiles, and the major axioms of consumerist culture (Figure 4); the other involves the influence of excessive intelligence in smart fabrics on the equation of human apparel (Figure 5).

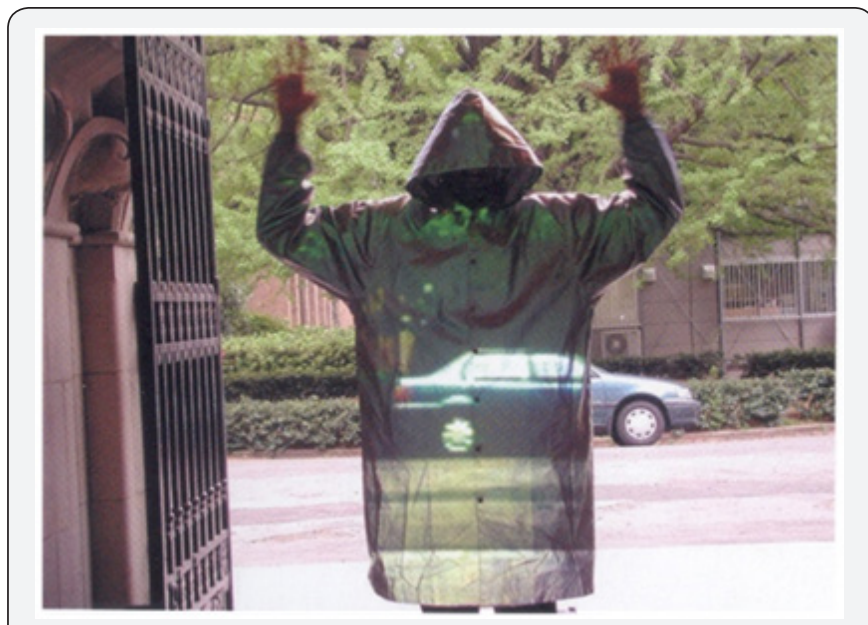

Figure 4: Susumu Tachi, Optical Camouflage, 2003

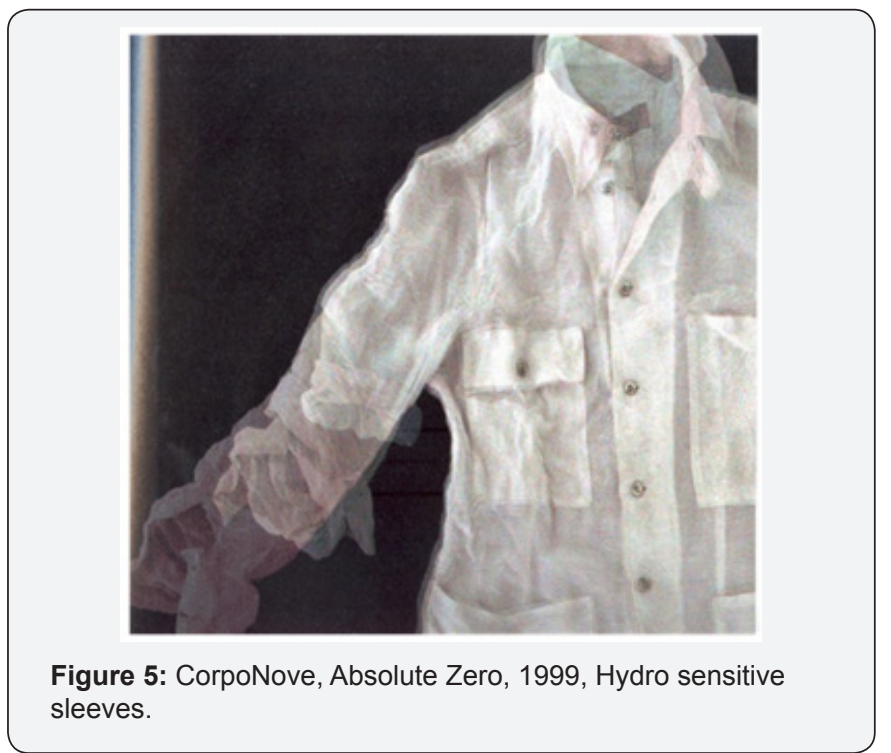

It is an exploration of the journey into the body's spraying to obtain an aptly designed covering (Figure 6) and the unknown or the accessibility of the virtual dress skills. An enchanting possibility is introduced by the contemplation of solar shirts which refresh their cut in real time, rendering their wearers independent of the stylistic aspect. Growable seasonal sleeves may engulf the wearer with a previously unfamiliar cultural and social bubble. A sweat-preventing shirt or a «forever-white» collar is bound to challenge the human consumerist urge, while being congruent with and enhancing the green inclination of restrained consumerism.

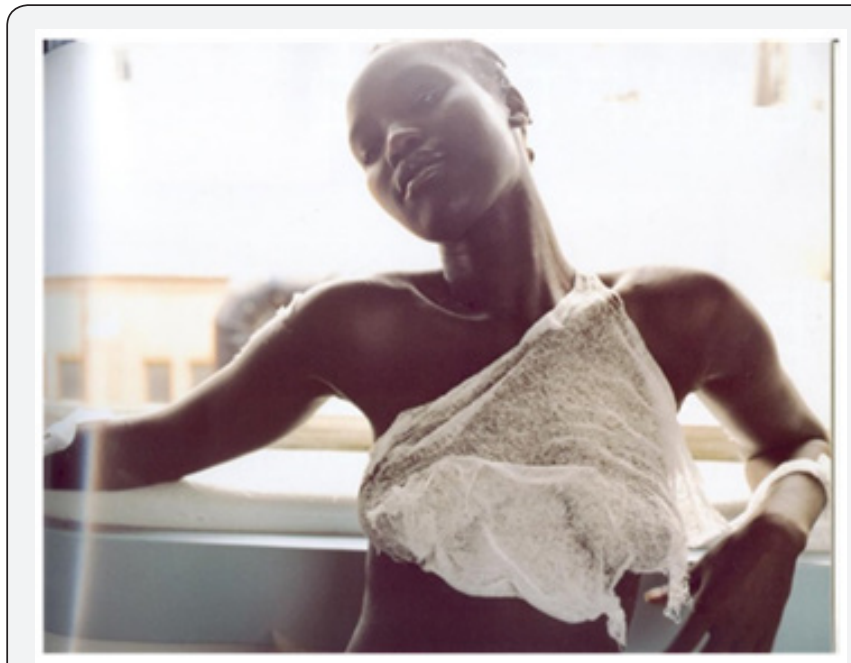

Figure 6: Mannel Torres, Fabrican, self-sprayed shirt, 2002.

The cyclical trickling of fashion products into the garment fields cannot blur the radical dichotomy between the two target audiences: those using apparel as body covering versus the consumers of fashion. One can hardly expect that the design of innovative solutions involving smart textiles will suppress the immanent human need for innovation. It is unlikely that the northern, white world will set the challenge for itself to define a timeless language of design which will dictate the possibility for a total garment to last a lifetime. It is, however, quite likely that the rest of the world's population will use such an intelligent garment as an existential solution, and it is also likely that then the relative size of this segment of the world's population will shake the balance of commercial currency.

If «The Shirt» can balance the wearer into a condition of month-long satiation by epidermal diffusion of concentrated food, for example, two concepts will be realized: the supercultural concept adhering to «comfort foremost,» and dismantling individual responsibility to the point of loss of control over substantial processes. These two side-effects are incongruent with the vision of life in a sustainable world. For disaster-stricken areas, however, «The Shirt» offers a real solution. Age-dependent clothing, as well as domestic textile, resistant to both dirt and wear, can alter the time division in the maintenance of the family unit, and redundify the washing machine. As the production costs of cellular communications technologies are expected to drop, it will be possible to reproduce a communicative solution in every random button. In such a case the need will arise to settle the dispute of one-time use with the demand to restrict the use of the earth's resources and represent the interests of the next generations.

Toward an era of life in a sustainable world, Bill McDonough \& Michael Braungart [13] suggest regarding the environmental issue as a design issue. Only if the design process takes heed of the practical, ideological, visual, and latent implications can the 
solution become an agent of social and environmental change [14-15].

\section{Conclusion}

Contemporary theories of material culture adhere to sustainable approaches on one hand, and on the other to the demand to harness æsthetics as an agent conducive to change in social space, rather than regard the future as an unknown scientific variable. Intelligent textiles may offer an opportunity for protected, independent life for the majority of people as an existential basis.

Hypothetically, one may see how the transformation of the notion of wash-and-wear into self-cleaning or no-wash clothing and mass production of dirt-repellent, wear-resistant textiles may introduce a change in the equilibrium of the fashion industry and interfere with the profitability of the corporate economy.

The intricate nature of intelligent applications in textile is bound to add yet another set of signs and meanings to the restricted discourse of apparel and the broader discourse of culture on high levels of freedom and define realms of awareness and action infused with additional dimensions. These realms of awareness and conceptualization are a cultural raw material which may be owned, calibrated, guided, and aimed at goals oriented at human society as a whole. The right of ownership to the assets of this technological development must be ruled in favor of the general public to ensure a change and prevent cynical use which will exploit the public.

Economic control of smart textiles will dictate new orders, relationships, and hierarchies, and will profit from the dissociation between ownership of the technology and the ownership over the cultural priorities. Technological research must harness itself to cast a social anchor that will provide innovation with a cultural, philosophical, and conceptual grasp more significant than the analysis of profit.

More than a mere technological possibility and industrial realization, the vision of smart-textile as social raw material aims at empowering the users, furnishing them with a vehicle which will re-define their social and cultural positioning and shift the gaze directed at them outside the classification of the allowed and possible.

Scholarly backing is required in order to predict the change in the patterns of visibility, behavioral modes, life style, and social structures accompanying the use of very smart textiles. Even perceptual norms may deviate from their natural boundaries and adopt irrational insights regarding the dimensions of human capacity or suffering.

\section{References}

1. Garrett Hardin (1968) The commons are shared assets in the environment, used and enjoyed by all, virtual, social and political spaces where people have a sense of belonging. For a theoretical background see: "The Tragedy of the Commons", Science 162: 12431248.

2. Xiaoming Tao (2000) "Smart technology for textiles and clothing introduction and overview". In: Xiaoming Tao(eds.), Smart Fibers, Fabrics, and Clothing, Wood head Publishing Limited, Cambridge, England, UK pp. 1-6.

3. (1990) Upstream in environmental theory indicates a process where planning and organization of knowledge precede actual moves. See: Donald Scherer (ed.), Upstream/Downstream Issues in Environmental Ethics, Temple UP, Philadelphia, US.

4. Schick T Joseph(1988) "NahalHemar Cave-Cordage, Basketry and Fabrics", ATIQOT 18, pp.31-43, Pl19, pp.4.

5. Jefferies Janis (1995) Text and Textile: Weaving Across the Borderlines. Textile Seismographs, Console des arts textiles du Quebec, Montreal, Canada.

6. Diana Crane (2000) Fashion and Its Social Agendas: Class, Gender, and Identity in clothing, The University of Chicago Press, Chicago, US pp. 67-97.

7. Barthes Roland (1983) The Fashion System, Hill and Wang, New York, USA.

8. Xiaoming Tao (2000) pp. 174-197.

9. Lena Berlin (2008) How will smart material affect our life in the future? in E + T + Textiles conference, The Swedish school of textiles, Riga.

10. Rogof Irit (1998) “Studying visual culture”, In: Mirzoeff Nicholas (Ed.), The Visual Culture Reader, Routledge, New York \& London, pp. 24-36.

11. Butler Judith (1993) Bodies that Matters, Routledge, New York.

12. Holly L Schrank (1973) Correlates of Fashion Leadership: Implications for Fashion Process Theory. The Sociological Quarterly 14(4): pp. 534543.

13. William McDonough, Michael Braungart (1998) The Next Industrial Revolution. Atlantic Monthly 282(4): pp. 82-92.

14. Ranciere Jacques (2011) "The thinking of dissensus: Politics and aesthetics" In: Bowman P and Stamp R (Eds.), Reading Ranciere: Critical dissensus, London, UK pp. 1-17.

15. Lefebvre Henri ([1974] 1991) The production of space (trans. D. Nicholson-Smith). Blackwell, Oxford, UK. 
This work is licensed under Creative Commons Attribution 4.0 Licens

DOI: 10.19080/CTFTTE.2018.04.555626
Your next submission with Juniper Publishers will reach you the below assets

- Quality Editorial service

- Swift Peer Review

- Reprints availability

- E-prints Service

- Manuscript Podcast for convenient understanding

- Global attainment for your research

- Manuscript accessibility in different formats ( Pdf, E-pub, Full Text, Audio)

- Unceasing customer service

Track the below URL for one-step submission https://juniperpublishers.com/online-submission.php 